\title{
Theoretical Performance Comparison between Inline, Offset and Twin Crankshaft Internal Combustion Engines
}

\author{
*Dr. Taj Elssir Hassan \\ **Dr.Abdelfattah Bilal
}

***Dr.Maisara Mohy Eldin Gasim

\begin{abstract}
The twin crankshaft engine is anew configuration of internal combustion engine that introduced to solve the engine liner wear problems, increase the engine efficiency and it has other advantages over conventional engines.

In this research, a computational work was carried out to compare the performance of three l engine configurations, namely, the conventional (inline) engine, the offset crankshaft engine and the twin crankshaft engine, of the same cylinder bore, speed, crank arm, piston mass and heat addition. The performance measured was the side thrust force that causes liner wear and the output torque.

Results showed that the twin crankshaft engine is superior in terms of torque which means it has larger efficiency than the other configurations.
\end{abstract}

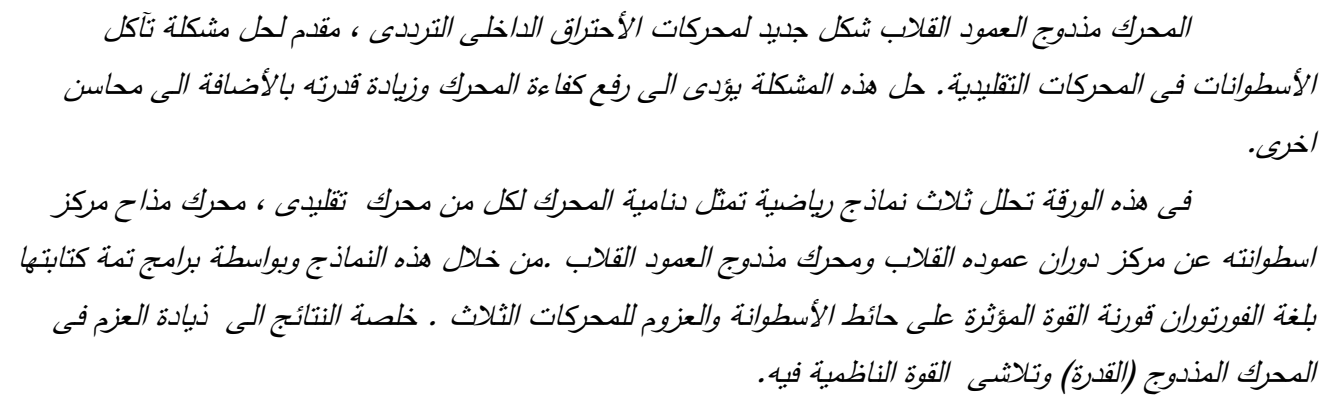

\footnotetext{
*Associate professor in Mechanical Eng.-Omdurman Islamic University

**Associate professor in Mechanical Eng.

*** Mechanical Engineering.
} 


\section{Introduction}

Twin crankshaft engine is solution for some conventional engines problems such as vibration, side thrust force, liners wear and as a result of all those factors engines poor efficiency [1].

Experimental work, which done in a twin crankshaft model built in Sudan university for science and technology-engineering faculty, proved the possibility of the twin crankshaft engine to reduce the liners wear, but what is the effect of the new arrangement in other engine's parameters, such like torque and efficiency? This work is trying to answer this question.

Starting from the equation of the state for an ideal gas, using Wiebbe function for heat release fraction, using piston force balance then, finally the engine's torque calculated.

\section{Calculating Gas Pressure [2]}

The equation of state for an ideal gas is:

$$
p v=m R T
$$

Taking the logarithm of both sides and differentiating with respect to crank angle gives

$$
\frac{1}{p} \frac{d p}{d \theta}+\frac{1}{V} \frac{d V}{d \theta}=\frac{1}{T} \frac{d T}{d \theta}
$$

The first law of thermodynamics in differential form for an ideal gas with constant specific heat is

$$
m c_{v} \frac{d T}{d \theta}=\frac{d Q}{d \theta}-p \frac{d V}{d \theta}
$$

Dividing the left -hand side by $m R T$ and the right side by $p V$, and rearranging then yields 
$\frac{1}{T} \frac{d T}{d \theta}=(\gamma-1)\left(\frac{1}{p V} \frac{d Q}{d \theta}-\frac{1}{V} \frac{d V}{d \theta}\right)$

Combining equation (2.4) and equation (2.2) and introducing of $d Q=Q_{i n} d x$ produces:

$\frac{d p}{d \theta}=-\gamma \frac{p}{V} \frac{d V}{d \theta}+(\gamma-1) \frac{Q_{\text {in }}}{V} \frac{d x}{d \theta}$

In practice, it is convenient to normalize the equation by letting

$\bar{p}=p / p_{1} \quad \tilde{V}=V / V_{1} \quad \tilde{Q}=Q_{i n} / p_{1} V_{1}$

In which case, equation (5) becomes

$$
\frac{d \tilde{p}}{d \theta}=-\gamma \frac{\tilde{p}}{\tilde{V}} \frac{d \tilde{V}}{d \theta}+(\gamma-1) \frac{\tilde{Q}}{\widetilde{V}} \frac{d x}{d \theta}
$$

Equation (2.7) is a linear first-order differential equation and can be solved by any numerical methods. Such as Rung-Kutta.

The volume $V$ and its derivative $d V / d \theta$ are a known function of the crank angle $\theta[3]$

$$
\begin{aligned}
& \tilde{V}=\left[1+\frac{r-1}{2}(1-\cos \theta)\right] / r \\
& \frac{d \tilde{V}}{d \theta}=\frac{(r-1)}{2} \frac{\sin \theta}{r}
\end{aligned}
$$

$r=$ the compression ratio $=V_{(\pi)} / V_{(0)}$

The fraction of heat release $x$ (assumed to take the form of a Wiebbe function) [3]. 


$$
x=1-\exp \left[1-\left(\frac{\theta-\theta_{s}}{\theta_{b}}\right)^{n}\right]
$$

$\frac{d x}{d \theta}=n(1-x)\left(\frac{\theta-\theta_{s}}{\theta_{b}}\right)^{(n-1)} / \theta_{b}$

To solve equation (2.7) and obtaining the values of $\mathrm{p}$ for both the compression and power strokes, a FORTRAN program was developed and used with the following prior values and assuming a spark ignition engine: $r=10, \gamma=1.3, \theta_{s}=-40^{\circ}, \theta_{b}=40^{\circ}, n=4, Q=20$

The results after running this program are in table (1) and figure (1).

Table (1): cylinder pressure

\begin{tabular}{|c|c|c|c|}
\hline Crank angle (deg) & Pressure (bar) & Crank angle (deg) & Pressure (bar) \\
\hline-180 & & 0 & 61.0034 \\
\hline-160 & 1.0001 & 20 & 57.6484 \\
\hline-140 & 1.0405 & 40 & 30.929 \\
\hline-120 & 1.1648 & 60 & 17.1119 \\
\hline-100 & 1.4098 & 80 & 10.6047 \\
\hline-80 & 1.861 & 100 & 7.3511 \\
\hline-60 & 2.7133 & 120 & 5.6201 \\
\hline-40 & 4.4301 & 140 & 4.6813 \\
\hline-20 & 8.0837 & 160 & 4.2134 \\
\hline
\end{tabular}




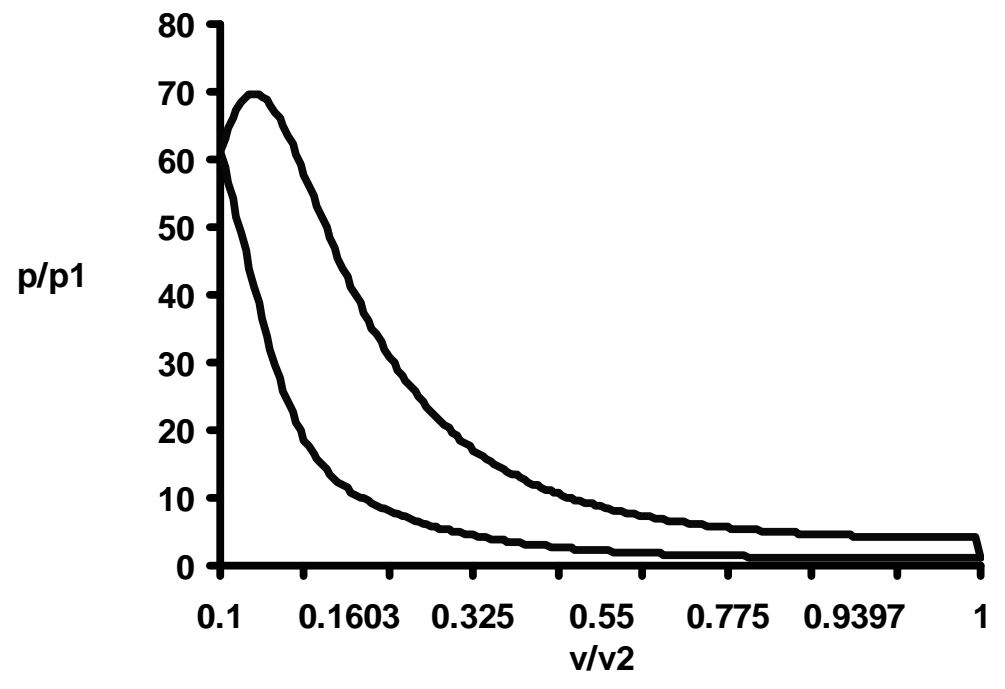

Figure (1): p-V diagram resulting from the program

\section{Inline Crankshaft Engine Performance}

Stroke $=.046 \mathrm{~mm}$, Bore $=.076 \mathrm{~mm}$

Length of connecting rod $=0.092=b$

Crank arm $=0.023 \mathrm{~mm}=\mathrm{r}$

Piston and part of connecting rod mass $=0.3 \mathrm{~kg}, \mu=0.5$

Speed of the engine $=2500 \mathrm{rpm}$

Piston force balance: 


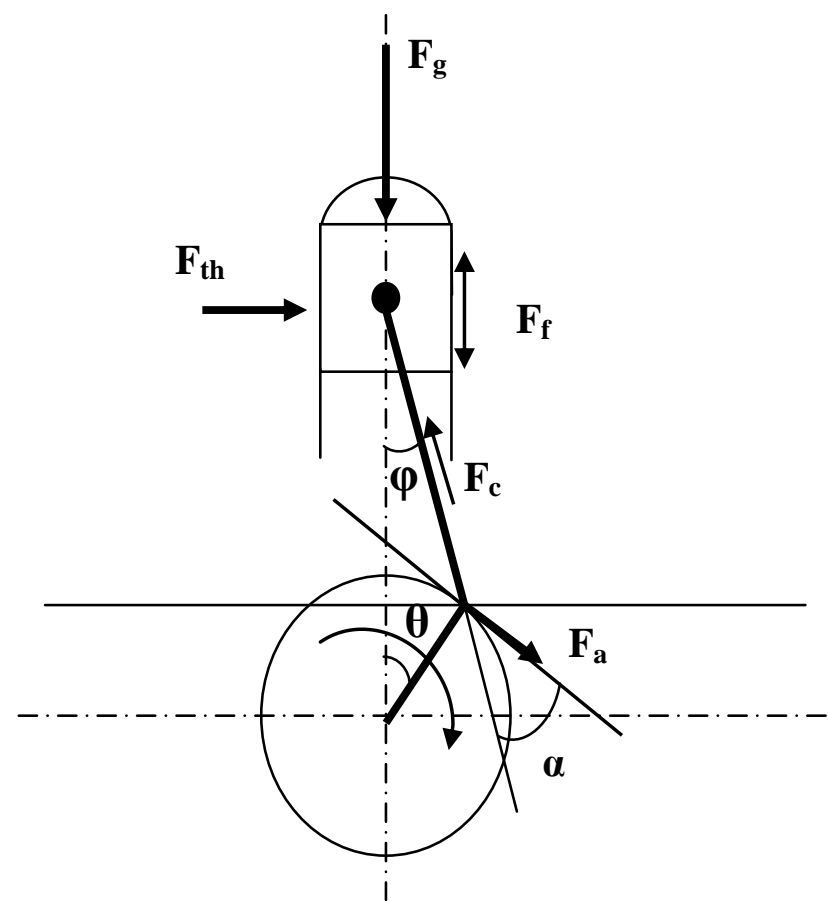

Figure (2): Piston Force Balance

Now [4]:

$F_{c}=\left[P * A-m * a \pm F_{f}\right] / \cos \varphi$

$a=r \omega^{2}\left(\cos \theta+\frac{\cos 2 \theta}{2 * b / r}\right)$

But:

$\operatorname{Sin} \varphi=r^{*} \sin \theta / b$

Then 


$$
F_{c}=\frac{P^{*} A-m^{*} a \pm F_{f}}{\cos \sin ^{-1}(r \sin \theta / b)}
$$

By taking the reaction of $F_{c}$ :

$F_{a}=F_{c} * \cos \alpha$

$F_{a}$ is the vertical component of $F_{c}$, which causes the torque.

But

$\alpha=90-(\theta+\varphi)$

Then

$F_{a}=F_{c} \cos \left(90-\left(\theta+\sin ^{-1}\left[r^{*} \sin \theta / b\right]\right)\right)$

The torque:

$T=F a * r$

The side thrust force

$$
\begin{aligned}
& F_{t h}=\left[P^{*} A-m * a \pm F_{f}\right] * \tan \varphi \\
& F_{f}=F_{t h} * \mu
\end{aligned}
$$

A FORTRAN computer program, also, made to calculate:

1- The torque.

2- The side thrust force.

Supposing that:

1- $\mathrm{P}_{1}$ from equation $(2.6)=1$ bar, so the pressure values from table 1 , will multiply by 100000 .

2-The values of the torque are through the compression and expansion strokes, so the crank angles are between -180 and 180 degrees. 
The results obtained when running the program are shown in table (2) and figures (5) and (6).

\section{Twin Crankshaft Engine Performance}

Stroke $=.047 \mathrm{~m}$

Bore $=.076 \mathrm{~m}$

Length of connecting rod $=0.16=b$

Crank arm $=0.023 \mathrm{~m}=\mathrm{r}$

Offset $=\mathrm{d}=0.03 \mathrm{~m}$

Piston and part of connecting rod mass $=0.5 \mathrm{~kg}$

Speed of the engine $=2500 \mathrm{rpm}$

Piston force balance:

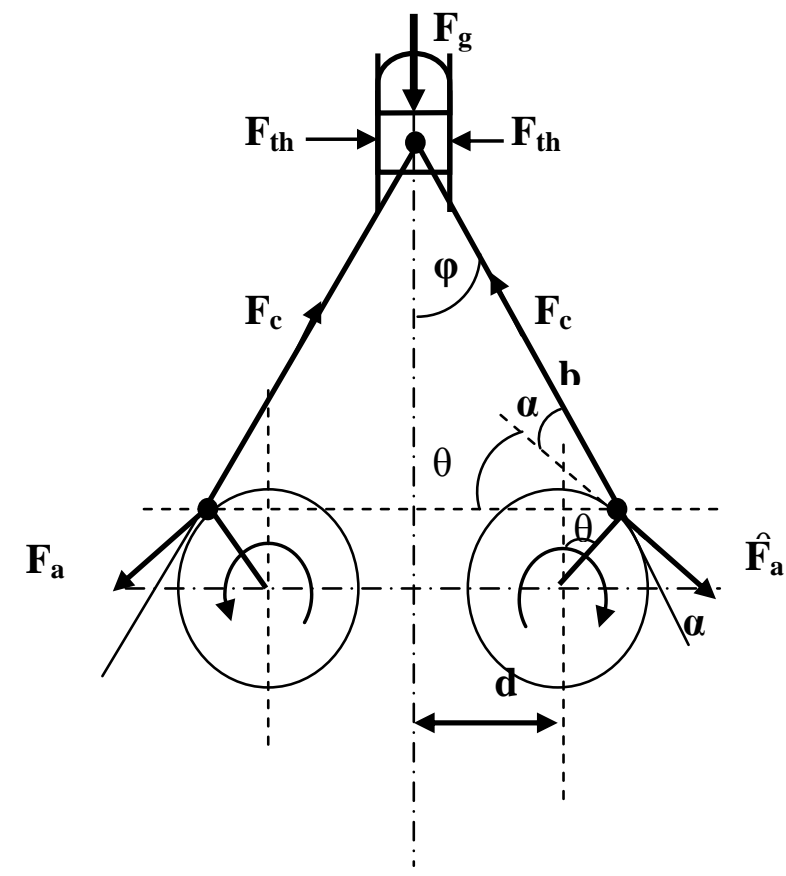

Figure (3): Twin Crankshaft Engine Piston's Force

Balance 
Now:

$F_{c}=\left[P^{*} A-m * a\right] / \cos \varphi$

$a=-r \cos \theta \omega^{2}-\left[(r \sin \theta+d)^{2} r^{2} \cos ^{2} \theta \omega^{2}\right] / \sqrt{\left(b^{2}-(r \sin \theta+d)^{2}\right)^{3}}$

$+\frac{(r \sin \theta+d) r \sin \theta \omega^{2}-r^{2} \cos ^{2} \theta \omega^{2}}{\sqrt{\left(b^{2}-(r \sin \theta+d)^{2}\right)}}$

But:

$\operatorname{Sin} \varphi=\left(r^{*} \sin \theta+d\right) / b$

Then

$F_{c}=\frac{P^{*} A-m^{*} a .}{2 * \cos \sin ^{-1}((r \sin \theta+d) / b)}$

By taking the reaction of $F_{c}$ :

$F_{a}=F_{c} * \cos \alpha$

$F_{a}$ is the vertical component of $F_{c}$, which causes the torque.

But

$\alpha=90-(\theta+\varphi)$

Then

$F_{a}=F_{c} \cos \left(90-\left(\theta-\sin ^{-1}\left[\left(r^{*} \sin \theta+d\right) / b\right]\right)\right)$

The torque for each crank:

$T=F a * r$

Then for both cranks: 
$T=2 * F a * r$

The side thrust force

$F_{t h}=\{[P * A / 2-m * a] / 2\} * \tan \varphi$

A computer program was written in FORTRAN language to calculate:

1- Torque

2- Side thrust force

The results obtained when running the program are shown in table (3) and figures (5) and (6).

\section{Offset One Crankshaft Engine Performance}

Stroke $=.047 \mathrm{~m}$

Bore $=.076 \mathrm{~m}$

Length of connecting rod $=0.16=b$

Crank arm $=0.023 \mathrm{~m}=\mathrm{r}$

Offset $=\mathrm{d}=0.01 \mathrm{~m}$

Piston and part of connecting rod mass $=0.5 \mathrm{~kg}$

Speed of the engine $=2500 \mathrm{rpm}$

Piston force balance: 


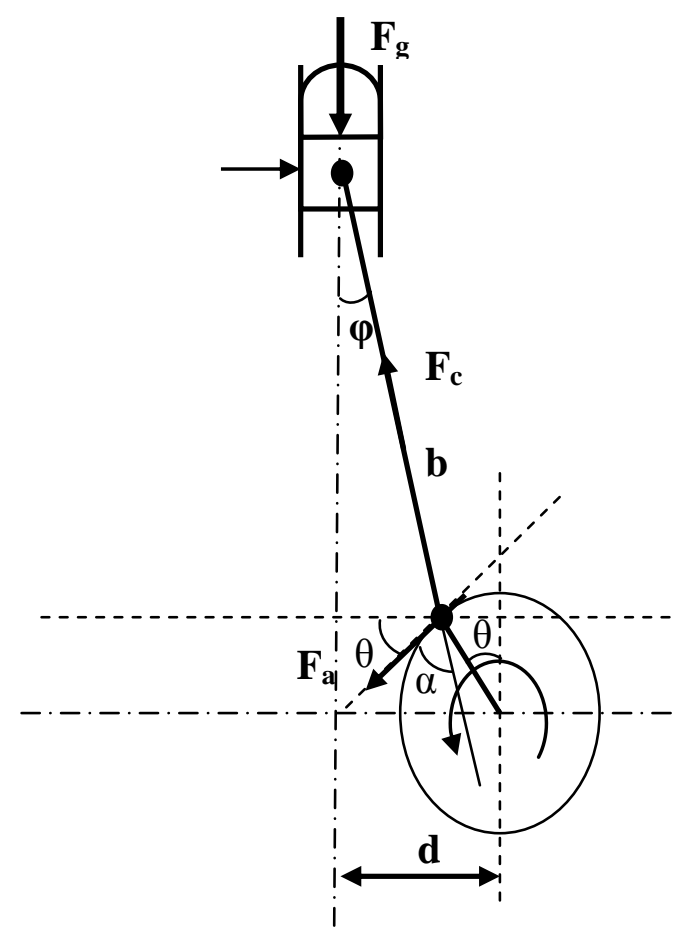

Figure (4): Offset Crankshaft Engine Piston's Force Balance

Now:

$$
\begin{aligned}
& F_{c}=\left[P^{*} A-m * a\right] / \cos \varphi \\
& a=-r \cos \theta \omega^{2}-\left[(r \sin \theta+d)^{2} r^{2} \cos ^{2} \theta \omega^{2}\right] / \sqrt{\left(b^{2}-(r \sin \theta+d)^{2}\right)^{3}} \\
& +\frac{(r \sin \theta+d) r \sin \theta \omega^{2}-r^{2} \cos ^{2} \theta \omega^{2}}{\sqrt{\left(b^{2}-(r \sin \theta+d)^{2}\right)}}
\end{aligned}
$$

But:

$\operatorname{Sin} \varphi=\left(r^{*} \sin \theta+d\right) / b$ 
Then

$F_{c}=\left[P^{*} A-m^{*} a\right] / \cos \sin ^{-1}\left[\left(r^{*} \sin \theta+d\right) / b\right]$

By taking the reaction of $\mathrm{F}_{\mathrm{c}}$ :

$F_{a}=F_{c} * \cos \alpha$

$F_{a}$ is the vertical component of $F_{c}$, which causes the torque.

But

$\alpha=90-(\theta-\varphi)$

Then

$F_{a}=F_{c} * \cos \left(90-\left(\theta-\sin ^{-1}\left[\left(r^{*} \sin \theta+d\right) / b\right]\right)\right)$

The torque:

$T=F a * r$

The side thrust force

$F_{\text {th }}=\left[P^{*} A-m * a\right] * \tan \varphi / 2$

A computer program was written in FORTRAN language to calculate:

1- Torque

2- Side thrust force

The results obtained when running the program are shown in table (4) and figures (5), (6). 


\section{Results}

The torque and side thrust force for the three engines arrangements calculated through the compression and expansion strokes are presented in table (2), (3) and 4 below. With figures (5), (6) are plots of the results:

Table (2): Inline Engine Performance

\begin{tabular}{|c|c|c|c|c|}
\hline $\begin{array}{l}\text { Crank } \\
\text { angle } \\
\text { (deg) }\end{array}$ & $\begin{array}{l}\text { Pressure } \\
\text { (bar) }\end{array}$ & $\begin{array}{l}\text { Acceleration } \\
\left(\mathrm{m} / \mathrm{s}^{2}\right)\end{array}$ & $\begin{array}{l}\text { Torque } \\
\text { (N.m) }\end{array}$ & Thrust force $(\mathrm{N})$ \\
\hline-180 & 1.0001 & -1370.93 & 0.0188 & 0.2734 \\
\hline-160 & 1.0405 & -1322.59 & -4.9832 & -74.3233 \\
\hline-140 & 1.1648 & -1166.83 & -9.6025 & -142.843 \\
\hline-120 & 1.4098 & -882.173 & -13.9532 & -200.405 \\
\hline-100 & 1.861 & -457.095 & -18.529 & -249.232 \\
\hline-80 & 2.7133 & 87.09 & -24.8855 & -306.033 \\
\hline-60 & 4.4301 & 684.753 & -36.0454 & -400.184 \\
\hline-40 & 8.0837 & 1233.843 & -53.4711 & -536.916 \\
\hline-20 & 18.6137 & 1622.212 & -74.0548 & -683.088 \\
\hline 0 & 61.0034 & 1762.631 & 0.0008 & 0 \\
\hline 20 & 57.6484 & 1622.212 & 238.8552 & 2203.208 \\
\hline 40 & 30.929 & 1233.843 & 221.5533 & 2224.665 \\
\hline 60 & 17.1119 & 684.753 & 150.9801 & 1676.212 \\
\hline 80 & 10.6047 & 87.09 & 98.8327 & 1215.407 \\
\hline 100 & 7.3511 & -457.095 & 65.5523 & 881.7399 \\
\hline 120 & 5.6201 & -882.173 & 43.4263 & 623.7161 \\
\hline 140 & 4.6813 & -1166.83 & 27.0395 & 402.2306 \\
\hline 160 & 4.2134 & -1322.59 & 13.2386 & 197.4526 \\
\hline
\end{tabular}


Table (3): Twin Engine Performance

\begin{tabular}{|c|r|r|r|r|}
\hline $\begin{array}{c}\text { Crank angle } \\
(\mathrm{deg})\end{array}$ & $\begin{array}{c}\text { Pressure } \\
\text { (bar) }\end{array}$ & $\begin{array}{c}\text { Acceleration } \\
\left(\mathrm{m} / \mathrm{s}^{2}\right)\end{array}$ & $\begin{array}{c}\text { Torque } \\
(\mathrm{N} . \mathrm{m})\end{array}$ & $\begin{array}{c}\text { Thrust force } \\
(\mathrm{N})\end{array}$ \\
\hline-180 & 1.0001 & -1329.49 & -4.8712 & 106.6013 \\
\hline-160 & 1.0405 & -1140.41 & -11.3239 & 72.8657 \\
\hline-140 & 1.1648 & -784.274 & -15.1451 & 44.0188 \\
\hline-120 & 1.4098 & -303.837 & -16.332 & 25.0065 \\
\hline-100 & 1.861 & 241.9036 & -16.5122 & 16.6336 \\
\hline-80 & 2.7133 & 786.322 & -18.8205 & 19.2514 \\
\hline-60 & 4.4301 & 1263.699 & -26.4484 & 43.4673 \\
\hline-40 & 8.0837 & 1617.158 & -37.4617 & 136.4797 \\
\hline-20 & 18.6137 & 1805.036 & -36.5813 & 526.5565 \\
\hline 0 & 61.0034 & 1804.429 & 117.5261 & 2554.899 \\
\hline 20 & 57.6484 & 1612.723 & 332.8618 & 3086.848 \\
\hline 40 & 30.929 & 1249.484 & 267.093 & 1954.327 \\
\hline 60 & 17.1119 & 758.4147 & 174.9526 & 1212.313 \\
\hline 80 & 10.6047 & 204.1759 & 113.1862 & 820.3818 \\
\hline 100 & 7.3511 & -340.097 & 74.4726 & 610.5778 \\
\hline 120 & 5.6201 & -808.72 & 47.6356 & 484.8568 \\
\hline 140 & 4.6813 & -1151.37 & 25.9865 & 393.3051 \\
\hline 160 & 4.2134 & -1332.05 & 6.6466 & 313.6734 \\
\hline & & & & \\
\hline
\end{tabular}

Table (4): Offset Engine Performance

\begin{tabular}{|c|c|c|c|c|}
\hline $\begin{array}{l}\text { Crank angle } \\
\text { (deg) }\end{array}$ & $\begin{array}{l}\text { Pressure } \\
\text { (bar) }\end{array}$ & $\begin{array}{l}\text { Acceleration } \\
\left(\mathrm{m} / \mathrm{s}^{2}\right)\end{array}$ & $\begin{array}{l}\text { Torque } \\
\text { (N.m) }\end{array}$ & Thrust force $(\mathrm{N})$ \\
\hline-180 & 1.0001 & -1340.36 & 1.1995 & 53.4329 \\
\hline-160 & 1.0405 & -1210.14 & -4.2827 & 93.6996 \\
\hline-140 & 1.1648 & -906.315 & -8.8653 & 125.3835 \\
\hline-120 & 1.4098 & -466.903 & -12.5062 & 148.3376 \\
\hline-100 & 1.861 & 55.713 & -16.1723 & 172.4656 \\
\hline-80 & 2.7133 & 600.0876 & -22.1027 & 219.0423 \\
\hline-60 & 4.4301 & 1100.513 & -33.5883 & 319.7136 \\
\hline-40 & 8.0837 & 1494.944 & -52.0204 & 504.7082 \\
\hline-20 & 18.6137 & 1735.105 & -76.8822 & 890.4061 \\
\hline 0 & 61.0034 & 1793.334 & -39.7915 & 1699.143 \\
\hline 20 & 57.6484 & 1663.992 & 196.2128 & 341.5777 \\
\hline 40 & 30.929 & 1362.393 & 205.6815 & -407.872 \\
\hline 60 & 17.1119 & 923.7077 & 149.7285 & -465.116 \\
\hline 80 & 10.6047 & 400.4283 & 103.4616 & -372.064 \\
\hline 100 & 7.3511 & -143.905 & 72.4165 & -267.835 \\
\hline 120 & 5.6201 & -643.585 & 50.9774 & -170.162 \\
\hline 140 & 4.6813 & -1038.67 & 34.1266 & -72.5778 \\
\hline 160 & 4.2134 & -1281.01 & 18.7574 & 30.9609 \\
\hline
\end{tabular}




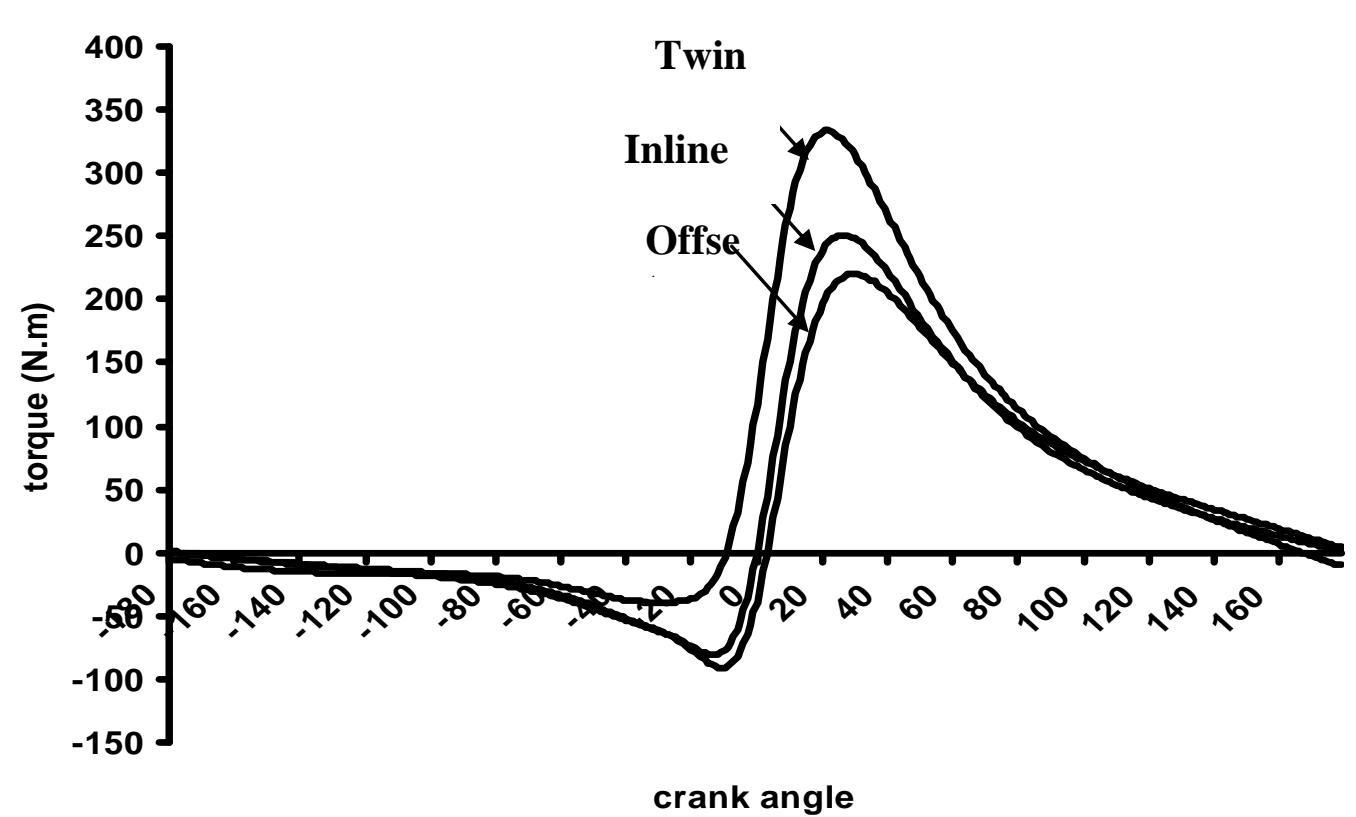

Figure (5): Torque Comparison between Inline, Offset and Twin Crankshaft Engines

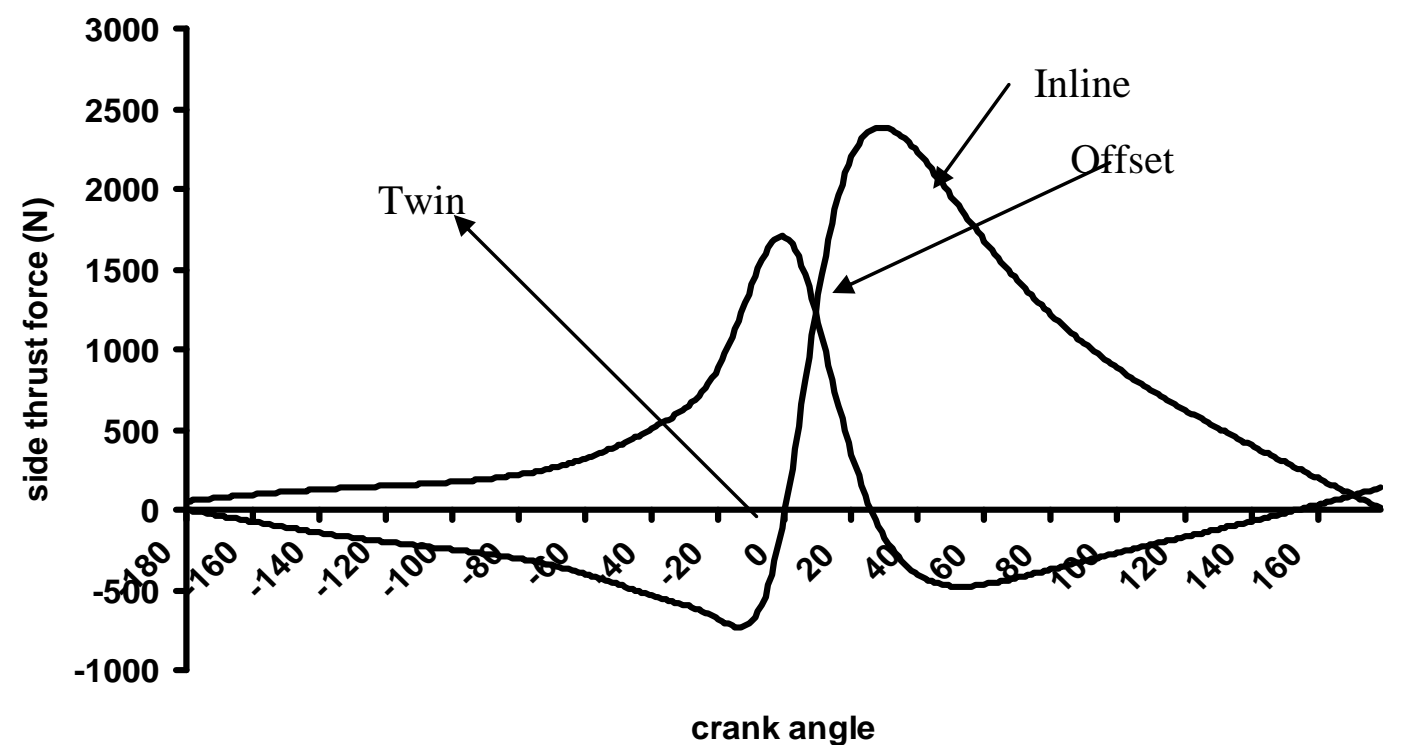

Figure (6): Side Thrust Force Comparison between Inline, Offset And Twin Crankshaft Engines 


\section{Discussion}

7.1 Figure (5) shows the torque comparison between inline (conventional) crankshaft engine, offset crankshaft engine and twin crankshaft engine.

The figure shows that the torque of twin crankshaft engine is larger than the inline crankshaft engine. And that can be explained by looking to the crank angle $\theta$, the angle between the force $F_{a}$ and extension of force $F_{c}$, which is $\alpha$, and the cylinder's pressure.

From the figure, the maximum torque occurs when $\theta=20^{\circ}$ and the cylinder pressure $=57.6484 \mathrm{bar}, \alpha=56.3^{\circ}$ in twin crankshaft engine. And when $\theta=20, \alpha$ $=65.1^{\circ}$ in inline crankshaft engine,

That means in twin crankshaft engine the angle $\alpha$ is smaller, and that gives a higher torque, see equations (3.6), (3.7), (4.6), (4.7).

In other words the twin crankshaft engine uses the cylinder pressure - in his highest values - better than the inline crankshaft engine.

7.2 Figure (6) shows the side thrust force comparison between the three engine arrangements.

In twin crankshaft case: there are too opposite forces, because of using two crankshafts, and that makes the resultant of the side thrust force equals zero.

In offset crankshaft case: the side thrust force is smaller than the inline crankshaft, and that is because of reducing the angle $\varphi$ in expansion stroke. See equations (3.9), (5.9). But unfortunately the torque reduces too; because of the increase of angle $\alpha$. see equation (5.6).

\section{Conclusions}

1. The twin crankshaft engine increases the torque and that means increases the efficiency.

2. The side thrust force in twin crankshaft engine equals zero.

3. The offset crankshaft engine decreases the side thrust force, when compared with the conventional engine. But it has a smaller torque. 


\section{Nomenclatures}

A Piston cross-section area

$c_{v} \quad$ Specific heat

$\mathrm{F}_{\mathrm{a}}$ Vertical component of $\mathrm{Fc}$

$\mathrm{F}_{\mathrm{c}}$ Connecting rod force

$F_{f}$ Friction force

$F_{g}$ Gas pressure force

th Side thrust force

$m$ Mass

$n \quad$ A parameter used to curve fit experimental data

$\mathrm{p}$ Pressure

P Cylinder pressure

$Q \quad$ Heat addition

$R \quad$ Gas constant

$T$ Temperature

$\mathrm{V}$ Volume

$x \quad$ Fraction of heat release

$\gamma \quad$ Specific heat ratio

$\theta \quad$ Crank angle

$\theta_{b} \quad$ Time scale of heat release

$\theta_{s} \quad$ Start of heat release

$\varphi \quad$ The angle between the connecting rod and the line joining the center of the crankshaft to the piston

$\alpha$ The angle between the force $\mathrm{Fa}$ and extension of force $\mathrm{Fc}$

$\mu \quad$ Friction factor

\section{References}

[1] Feuling; James J Contra-rotating twin crankshaft internal combustion engine. U.S paten 5,595.147,

[2] Colin R. Ferguson, Internal Combustion Engines-Applied Thermo sciences, John Wiley \& Sons, 1986.

[3] www. Engr.colostate. edu, slider crank model

[4] J. Hannah \&R.C. Stephens, Mechanics of Machines, Edward Arnold Ltd, 1984.

[5] Mike Rollins, What is The Speed of a Piston with an offset crankshaft, Rollins@wfu.edu. 